\section{Precise Placement and Variable Rate Fertilizer Application Technologies for Horticultural Crops}

\author{
Arnold W. Schumann ${ }^{1}$
}

ADDITIONAL INDEX WORDs. nutrients, site-specific, precision agriculture, sensors, GPS/GIS

SUMMARY. Fertilizer spreaders capable of variable rate application are increasingly important for enhancing nutrient management in horticultural crops because they improve placement and increase nutrient uptake efficiency. Matching applied fertilizer to fertilizer requirements represents a significant input cost saving for the grower and a reduction in potential pollutant loading to ground and surface water. Variable rate fertilization (VRF) is a precision agriculture technology made possible by embedded high-speed computers, accurate Global Positioning System (GPS) receivers, Geographic Information Systems (GIS), remote sensing, yield or soil maps, actuators, and electronic sensors capable of measuring and even forecasting crop properties in real time. For tree crops like Florida citrus (Citrus spp.), the most important function of the VRF spreader is to detect and avoid fertilizing spaces of the orchard not occupied by trees. Treeless spaces are becoming more common in Florida as diseases such as citrus greening (Candidatus Liberibacter asiaticus) and canker (Xanthomonas axonopodis) cause the removal of thousands of trees every year. VRF works best under those conditions. Because VRF exploits crop and soil variability, it has no value in a perfectly uniform field. VRF enables smaller trees including resets to be fertilized at lower, most appropriate rates, thus minimizing any excess application. This article examines the existing knowledge on using precision agriculture and variable rate technology to keep water and nutrients in the root zone of horticultural crops, thus facilitating maximum uptake efficiency.

$\mathrm{P}$ recision agriculture (PA), as the name implies, is useful technology for growing and fertilizing horticultural crops more precisely or efficiently, thereby retaining water and nutrients in the root zone. Three techniques with which PA can help achieve this objective are 1) the collection of spatial data from pre-existing conditions in the field (e.g., remote sensing, canopy size, or yield measurement), 2) the application of precise fertilizer amounts to the crop when and where needed, and 3 ) the recording of detailed logs of all fertilizer applications for spatial and temporal mapping. Thus, PA can help us determine exactly where to place nutrients and how much to apply, and then track the applied nutrients with accumulation logs and GIS maps.

Site-specific management (SSM) is a crop management strategy of PA that addresses within-field variability by optimizing inputs such as pesticides and fertilizers on a point-by-point or small area basis. Thus, nutrients are

Soil and Water Science Department, University of Florida, Citrus Research and Education Center, 700 Experiment Station Road, Lake Alfred, FL 33850

${ }^{1}$ Corresponding author. E-mail: schumaw@ufl.edu. applied only as needed within a field, rather than uniformly across the entire field for the average field requirements. Successful implementation of SSM relies on accurate quantification of the spatial variation of important soil and crop factors and their interpretation into required variable rates of agrochemicals that are targeted only under crop canopies and therefore over root zones. Various sensors are used to quantify this spatial variation which includes soil electrical conductivity (EC), yield, canopy size, and canopy color. Sensor data are real-time ("on-the-go") from soil or crop measurements taken directly from the application equipment, or they can be previously measured data such as from remote sensing surveys and yield mapping, both of which are used to create prescription maps for future site-specific applications of agrochemicals. Real-time SSM generally does not need GPS data because decisions about agrochemical rates and crop target are made on the spot at the time of the measurement. Prescription map SSM needs GPS technology so that the correct field location, which matches with a prescribed rate on the map, can be located accurately. Both types of SSM are widely used for fertilizing agronomic and horticultural crops. Precision agriculture instruments such as variable rate or irrigation controllers automatically keep detailed computerized records or logs of how much fertilizer or water was applied when and where. Good record keeping is crucial for instant accountability, plotting historical trends, and ultimately, better management of nutrients and water.

SSM implemented as VRF is one of the best PA tools for keeping nutrients in the root zone because it simultaneously optimizes nutrient rates and placement for a particular crop. Nevertheless, large yield increases resulting from VRF have been quite difficult to demonstrate consistently in most crops. However, input cost savings due to reduced fertilizer and fuel consumption and environmental benefits due to the resulting reduction in nutrient loadings per hectare are immediate and well documented. The objective of this article is to examine the PA and variable rate technologies that can be used to maximize nutrient and water uptake efficiency in horticultural crops by keeping water and nutrients in the root zone.

\section{Components of precision agriculture technology}

Modern PA technology provides the tools for more efficient nutrient

\begin{tabular}{llll}
\hline $\begin{array}{l}\text { Units } \\
\begin{array}{l}\text { To convert U.S. to SI, } \\
\text { multiply by }\end{array}\end{array}$ & U.S. unit & SI unit & $\begin{array}{l}\text { To convert SI to U.S., } \\
\text { multiply by }\end{array}$ \\
\hline 0.4047 & $\mathrm{acre}(\mathrm{s})$ & $\mathrm{ha}$ & 2.4711 \\
0.3048 & $\mathrm{ft}$ & $\mathrm{m}$ & 3.2808 \\
0.0283 & $\mathrm{ft}^{3}$ & $\mathrm{~m}^{3}$ & 35.3147 \\
2.54 & inch(es) & $\mathrm{cm}$ & 0.3937 \\
25.4 & inch(es) & $\mathrm{mm}$ & 0.0394 \\
1.1209 & lb/acre & $\mathrm{kg} \cdot \mathrm{ha}^{-1}$ & 0.8922 \\
1 & $\mathrm{ppm}$ & $\mathrm{mg} \cdot \mathrm{L}^{-1}$ & 1 \\
2.2417 & ton/acre & $\mathrm{t} \cdot \mathrm{ha}^{-1}$ & 0.4461
\end{tabular}


management of horticultural crops, which include remote sensing, the GPS, GIS, mobile, and embedded computing, and soil or crop prescriptive mapping.

Remote SENSING. Remote sensing typically involves acquiring and processing satellite or aerial images photographed in the visible or nearinfrared portions of the electromagnetic spectrum. Useful information derived from remote sensing could include crop variability, canopy size and health, soil type, and water stress. Figure $\mathrm{l}$ is an example aerial image from a free online GIS program (Google Earth ${ }^{\mathrm{TM}}$; Google, Mountain View, CA) showing the extent of citrus canopy growth variability across different soil series in an orchard. The white unproductive soil series in the middle is St. Lucie fine sand, while the surrounding darker colored more productive soil series are Myakka, Tavares, and Placid fine sands. A frequently used calculation applied to aerial photographs containing the near-infrared (NIR) and red bands of the electromagnetic spectrum is the normalized difference vegetation index [NDVI (Eq. 1)].

$$
N D V I=\frac{N I R-r e d}{N I R+r e d}
$$

The NDVI is useful to highlight green vegetation in aerial photographs and can also help to discriminate healthy productive crops (relatively green) from stressed unproductive crops [relatively yellow or in this case, red (Fig. 2)]. Johnson et al. (2001) evaluated the use of airborne, digital, multispectral imagery for delineation of subblock management zones in vineyards. They used NDVI to delineate low, moderate, and high growth vigor zones. Once the relationships between the remotely sensed, NDVI and the soil and crop properties at selected ground truth points have been established, additional aerial or satellite images could be used to assess the extent of soil and crop variability in neighboring fields. The productivity classes in Fig. 2 could also be converted into nutrient management zones once the nature of the variability is better understood.

GEOGRAPHIC INFORMATION SYSTEMS AND GLOBAL POSITIONING sYSTEMS. A GIS is a computerized "graphic database" allowing storage,

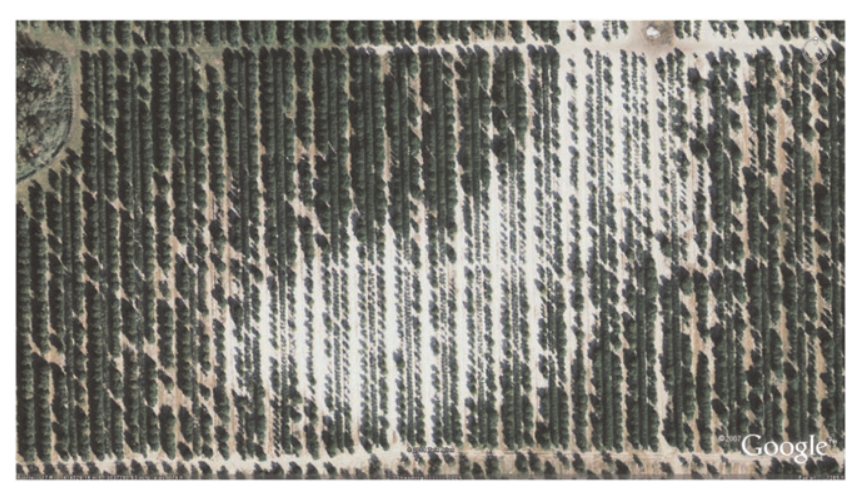

Fig. 1. Color aerial photograph of a citrus orchard in Hardee County, FL, showing the unproductive white-colored St. Lucie fine sand soil series in the center of the field.

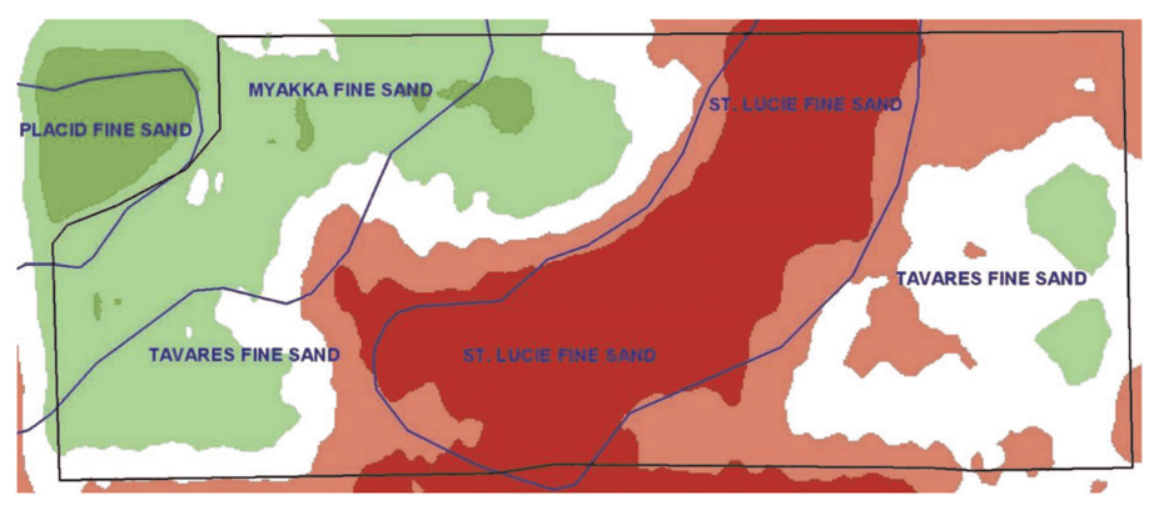

Fig. 2. Map of five productivity zones in a citrus orchard (Fig. 1) calculated from remotely sensed color-infrared aerial photography and the normalized difference vegetation index (NDVI). Dark green is most productive; dark red is least productive.

retrieval, display, and processing of any digital images or drawings with known positions on the earth's surface. The NDVI map in Fig. 2 was produced with the GIS software (Arcview 3.2; ESRI, Redlands, CA). Location, or georeferencing of data, maps and object images with the GPS is an essential prerequisite for meaningful processing and display on a GIS. The GPS is the only fully functional Global Navigation Satellite System (GNSS) and was developed by the U.S. Department of Defense. With a constellation of at least 24 medium earth orbit satellites that transmit precise microwave signals, the system enables a GPS receiver to determine its location to within $10 \mathrm{~m}$, as well as speed, direction, and time anywhere on earth. For the higher measurement accuracy of less than one meter required in variable rate fertilization of horticultural crops, the GPS calculation is further enhanced with differential correction, as implemented in a
Differential Global Positioning System (DGPS) receiver.

MobILe COMPUTING AND DATA STORAGE. Mobile or handheld computers are indispensible for recording field observations during scouting, leaf sampling, or soil surveying. When used in conjunction with GPS and GIS software, the handheld computer can be used for navigation in the field, which allows location and marking of plants, plots, soil types, or other information contained in the GIS (Fig. $3)$. Some handheld computers have an integrated GPS receiver, making the device ideal for field scouting and navigation.

Embedded microcontrollers are specialized computers used to control and automate specific processes in PA. Examples are the computer controllers for variable rate fertilization or automatic irrigation (Fig. 3). These computers are usually built to very robust standards for field work and have limited user interfaces but 

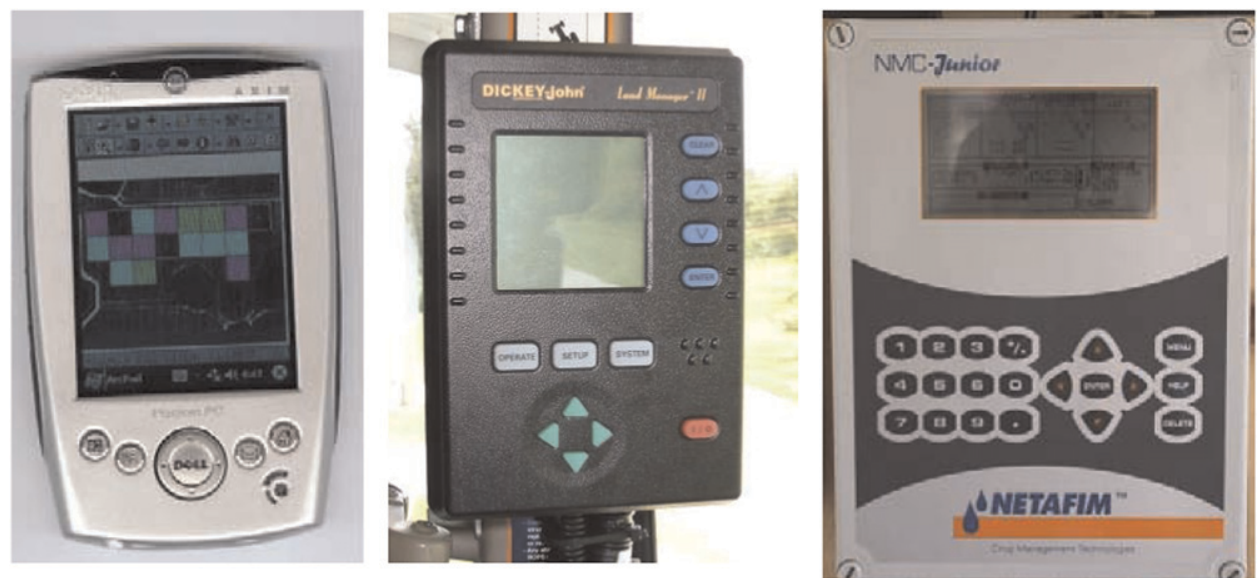

Fig. 3. Examples from left to right of a hand-held computer with Arcpad Geographic Information System software (ESRI, Redlands, CA), variable rate controller for a fertilizer spreader, and an automatic irrigation system controller.

powerful automatic data logging capabilities for recording all fertilizer or water applications.

SOIL, CROP YIELD, AND CANOPY MAPPING. Ground-based sensor surveying and mapping of soils, crop yield, and canopy characteristics is an alternative to remote sensing. These sensing methods collect georeferenced data about the soil and crops to characterize spatial variability and develop SSM programs. Soil mapping with geophysical survey or electromagnetic induction (EMI) instruments such as the EM38 (Geonics, Mississauga, ON, Canada), or the Veris 3000 (Veris Technologies, Salina, KS) allows rapid collection of georeferenced apparent soil EC $\left(\mathrm{EC}_{\mathrm{a}}\right)$ data in the field. Soil $\mathrm{EC}_{\mathrm{a}}$ can be correlated with chemical and physical properties of soil profiles such as salinity or groundwater levels. Soil data are usually collected from an EMI instrument pulled behind a vehicle driving in a predetermined path through the fields. Cambouris et al. (2006) evaluated the efficiency of $\mathrm{EC}_{\mathrm{a}}$ for delineating homogenous soil management zones for potato (Solanum tuberosum) production and they found significant differences in soil water content, some soil physicochemical properties [soil organic matter, soil phosphorus, and soil $\mathrm{pH}$ ], and in potato yields between two management zones. Available soil water is a good indicator of potential productivity and can be used as a tool to delineate management zones. Ojeda et al. (2005) used water potential to delineate management zones in viticulture and found reduction in vigor and yield with decreasing water availability. Schumann and Zaman (2003) used an EM38 instrument to successfully calibrate and map the depth of shallow groundwater in a citrus orchard (Fig. 4). Knowledge of the variation in water table in a field could be used to improve soil drainage and to predict where citrus roots and nutrients might be impacted by flooded conditions.

Georeferenced soil grid sampling has proven to be an effective tool in defining soil variability within a field. Once critical soil or nutrient properties are identified, maps can be developed and prescriptive steps can be taken to address field problems as needed for each location. Precision maps can be produced based on soil or crop properties and the field can be divided into management zones where variable rates of fertilizers can be applied according to the prescription map. A management zone can be defined as a subregion of a field that expresses a homogeneous combination of yield limiting factors for which a single rate of a specific crop input is appropriate (Doerge, 1999). Since soil type or organic matter is a major factor in causing yield variability, a field can be divided into different characteristic zones for variable rate application of fertilizer or water. Babcock and Pautsch (1998) compared single rate and variable rate application of fertilizers in corn (Zea mays), based on soil types. They found that applying variable rates would increase yield by 0.05 to 0.5 bushels per acre, and would reduce fertilizer costs by $\$ 1.19$ to $\$ 6.83$ per acre.
The spatial variation of soil and crop properties affects the yield of the crop and thus affects variation in profits when whole fields are managed with the same farm practices. Spaans and Quiros (2003) divided a banana (Musa spp.) plantation into different zones based on profit maps and found a good correlation between the yield and soil properties from the zones.

Automated crop yield map data are most often collected at the time of harvesting with mobile-embedded computers and sensors mounted on harvesting machinery. Typically optical or weighing sensors are used to detect and quantify the stream of crop harvested being collected by a mechanical harvester while a DGPS records the positions of the measured yield data for mapping on a GIS. Using a weighing device with load sensors, Pelletier and Upadhyaya (1999) found that there were significant spatial variations in processing tomato (Solanum lycopersicum) yield over a field (Fig. 5). The lowest 20\% yielding area within a field produced less than half the tomatoes compared with the highest $20 \%$ yielding area within the same field.

Computerized canopy measurement sensors have been used for rapid assessment of tree canopy heights and volumes in whole citrus orchards for GIS mapping and development of variable rate prescription zones (Schumann and Zaman, 2005; Zaman and Schumann, 2005). Leaf nutrient content, particularly nitrogen $(\mathrm{N})$ concentrations in crop canopies, can be estimated by sensing and 


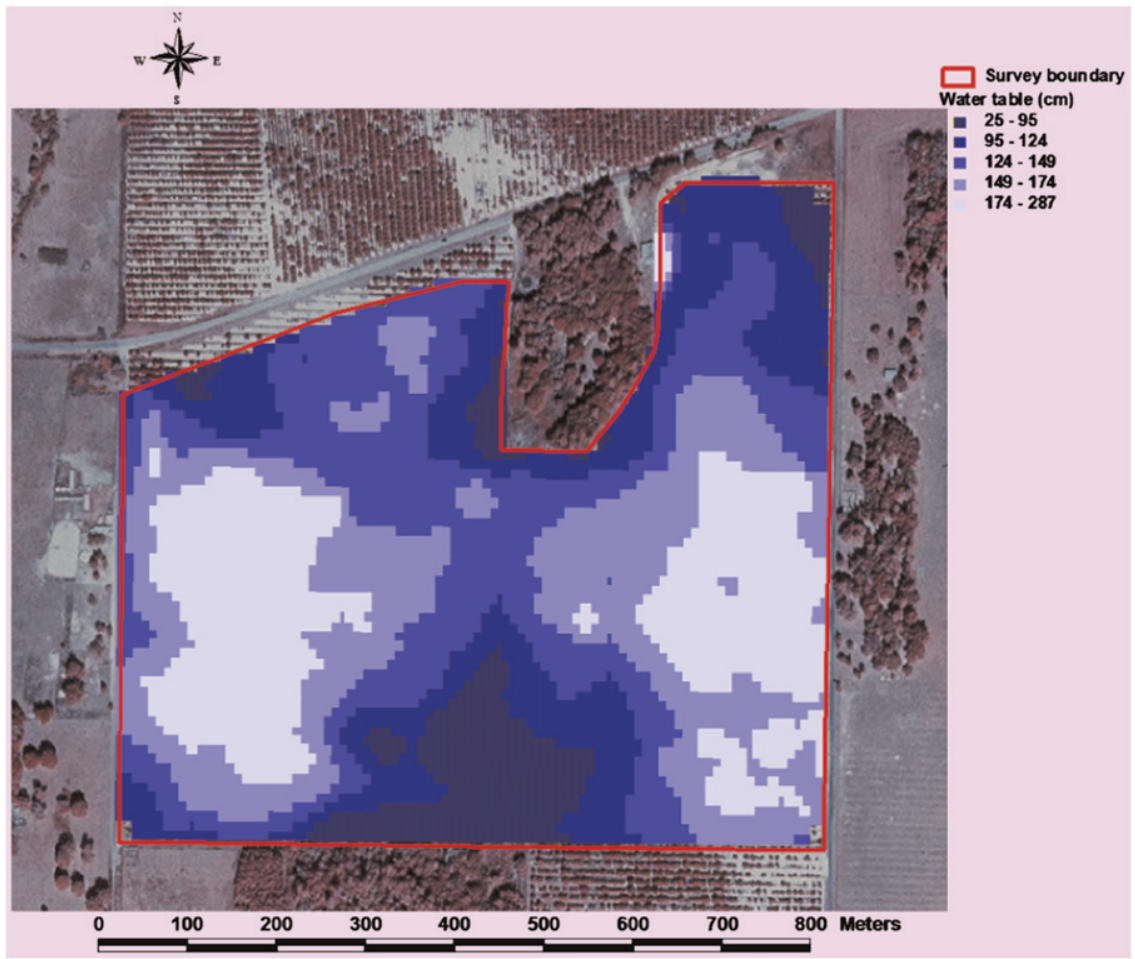

Fig. 4. Groundwater map of a citrus orchard obtained from detailed ground conductivity measurements taken with an EM38 instrument (Geonics, Mississauga, ON, Canada), and Differential Global Positioning System (DGPS) antenna mounted on a vehicle (Schumann and Zaman, 2003); $1 \mathrm{~cm}=0.3937$ inch; $1 \mathrm{~m}=3.2808 \mathrm{ft}$.

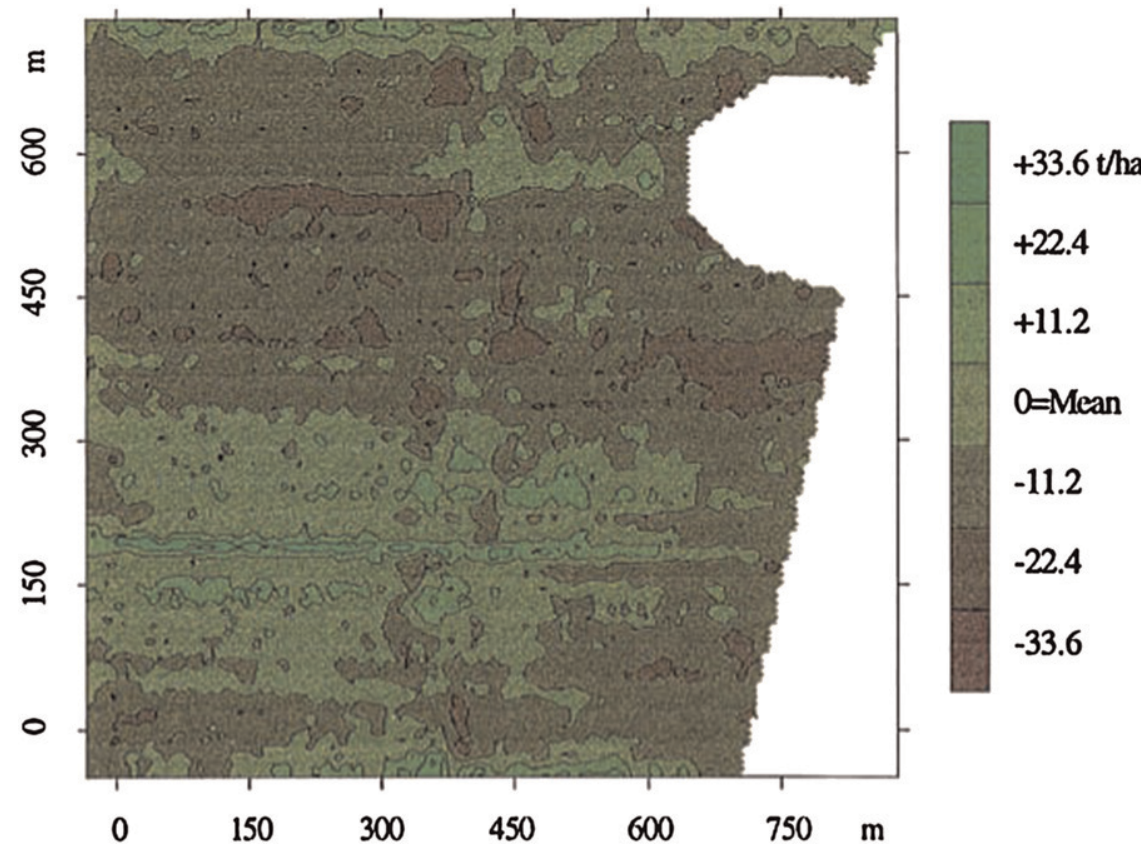

Fig. 5. A yield map obtained using a weighing tomato yield monitor. The map shows deviation from the mean yield of $88 \mathrm{t} \cdot \mathrm{ha}^{-1}$ [Pelletiera and Upadhyaya, 1999 (reproduced with permission) $] ; 1 \mathrm{~m}=3.2808 \mathrm{ft} ; 1 \mathrm{t} \cdot \mathrm{ha}^{-1}=0.4461$ ton/acre.

quantifying the greenness or amount of chlorophyll in the foliage (Jifon et al., 2005). Optical instruments like the Greenseeker (Ntech Industries,
Ukiah, CA) or the Minolta SPAD (Konika Minolta, Ramsey, NJ) use the NDVI calculation (Eq. 1) with a ground-based sensor to determine the N sufficiency of crop canopies for GIS mapping and prescriptive variable rate nutrient application.

\section{Variable rate application technologies}

Variable rate application of granular fertilizers allows improved placement in root zones and rate matching of fertilizers to crop requirements (Schumann et al., 2006a, 2006b). The two main functions of VRF are 1) to find the best fertilizer rate to match the crop and soil requirements and 2) to place the fertilizer as accurately as possible in the root zone under the canopy. This implies that no fertilizer is ever applied to bare soil where there are no active crop roots to absorb the nutrients. Figure 6 illustrates the potentially large amount of fertilizer that would be wasted in a citrus orchard not using VRF. A wider-spaced crop can save more fertilizer with VRF than a densely planted crop (Fig. 6). Recent studies in Florida citrus have demonstrated up to $40 \%$ reduction of fertilizer consumption in widely spaced $(10.7 \times 5.3 \mathrm{~m})$ orchards when using VRF (Zaman et al., 2005). Fruit yields and foliage nutrient levels were not diminished because the applied nutrient rate per tree was still optimal.

VRF METHODS AND TYPES OF FERTILIZER APPLICATORs. Applicators used for variable rates of granular fertilizers include spinner and pneumatic spreaders. Spinner applicators normally vary only one product rate at a time by changing the gate opening or changing the speed of the conveyor belt. However, spinner applicators for horticultural fruit crops such as citrus typically have independent left and right spinners and two conveyor belts, so that two rows of trees may simultaneously receive their own prescribed rate of fertilizer. Pneumatic applicators have centrally located bins and air tubes lead from a metering unit to the point of discharge through which fertilizers are suspended in the air stream and they can apply single or multiple products.

Liquid fertilizer applications can be made through most pesticide or herbicide spray booms for small vegetable crops provided that the fertilizer solution does not harm the foliage or stems of the crop. Narrow-angle 


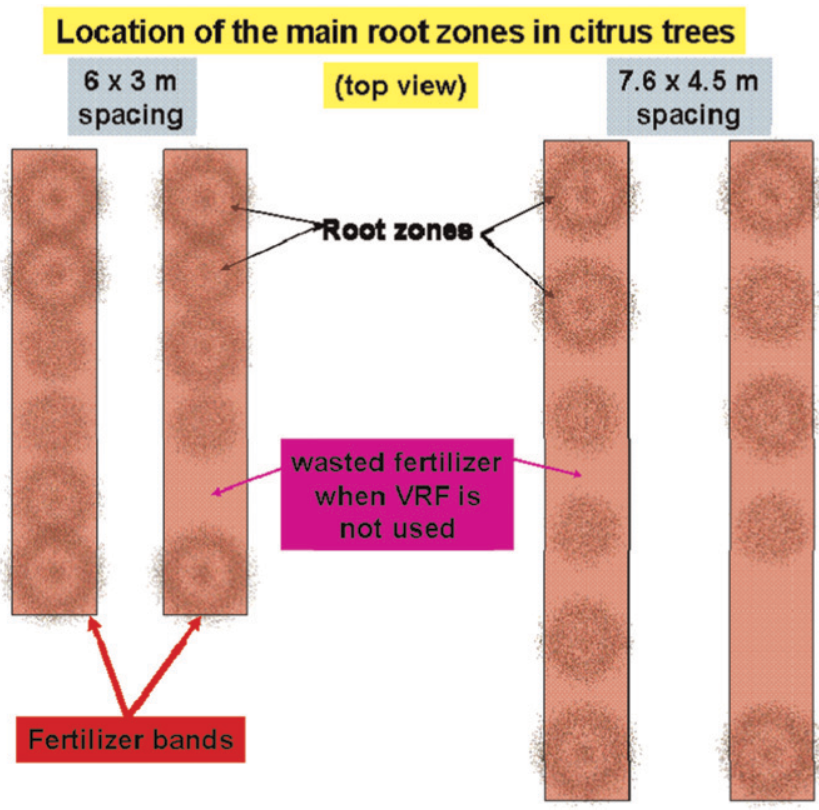

Fig. 6. Schematic diagram of an overhead view showing the wasted fertilizer that is not placed in root zones when fertilizing citrus tree rows with equipment not using variable rate technology; $1 \mathrm{~m}=3.2808 \mathrm{ft}$.

fan nozzles and drop-arms are used instead of broadcast cone nozzles along the spray boom to concentrate the fertilizer solution safely in the root zone of each row rather than spraying the entire field. Further improvements could be made by triggering each nozzle individually to spray fertilizer only when a crop plant has been detected under that nozzle and to regulate the dose according to the crop requirement. Giles and Slaughter (1997) developed a precision, ground-based applicator of foliar sprays to rows of small plants and validated it on tomato and lettuce (Lactuca sativa). They developed a machine vision guided spray boom system with servo control for nozzle angle and spray pattern width to spray pesticide and found that the precision system allowed spray application rates to be reduced by $66 \%$ to $80 \%$ and increased spray deposition efficiency on the target plants by 2.5 to 3.7 times greater than conventional broadcast spraying.

REAL-TIME SENSORS FOR VRF. Development of real time sensors to monitor critical parameters can complement map-based data. Sensors to measure soil fertility, soil water content, plant stress, or pest populations could allow management decisions to be implemented automatically with appropriate control technology and management. Plant $\mathrm{N}$ can be estimated using spectral reflectance measurements and $\mathrm{N}$ demand can be rapidly mapped. Pfenning et al. (2007) scanned the leaves of two broccoli (Brassica oleracea var. italica) cultivars Parthenon and Marathon, with a digital imager and measured reflectance and their results indicated a possibility of continuous measuring of leaf $\mathrm{N}$ content to adjust fertilizer application in real time. Alchanatis et al. (2005) developed a multispectral sensor, and the signal processing algorithm to provide real-time assessment of $\mathrm{N}$ status of 'Jubilee' sweet corn (Z. mays). Kim et al., (2002) used real-time $\mathrm{N}$ sensing and fertilization using a multispectral imaging sensor connected with a variable rate liquid application system for supplemental $\mathrm{N}$ supply to corn crops, thus improving the crop $\mathrm{N}$ status and increasing the yield over most plots.

Elings et al. (2004) used plant sensors for photosynthesis, radiation interception and fresh growth rate in greenhouse experiments with tomato. Results indicated that the greenhouse monitoring and control system offers good prospects for efficient control of water and nutrients. Measuring water and $\mathrm{N}$ in real time and adjusting irrigation and fertilizers based on the real-time data can be very helpful to maintain water and nutrients in the root zone of crops.

Customized ReAL-Time VRF BLENDING OF INDIVIDUAL NUTRIENTS. Radite et al. (2000) developed and tested a blending variable rate applicator in rice (Oryza sativa) paddy fields. The equipment could apply accurate varying rates of two different granular fertilizers using a broadcast type granular applicator with $12 \mathrm{noz}$ zles supplied from six metering devices. A variable rate applicator that can simultaneously apply varying rates of two liquid fertilizers was tested by using a control system on a sidedressing applicator (Yang, 2001). Grain sorghum (Sorghum bicolor) was fertilized by applying two uniform and one variable rate fertilizer treatment. Mean application rate errors for the two fertilizers $(32 \mathrm{~N}-0 \mathrm{P}-0 \mathrm{~K}$ and $11 \mathrm{~N}-16.2 \mathrm{P}-0 \mathrm{~K})$ were, respectively, $2.5 \%$ and $5.2 \%$ in 1997 and $2.8 \%$ and $5.8 \%$ in 1998. Sedlak et al., (2001) applied phosphorus (53 to $158 \mathrm{~kg} \cdot \mathrm{ha}^{-1}$ ), and potassium (0 to $336 \mathrm{~kg} \cdot \mathrm{ha}^{-1}$ ) fertilizer from separate bins of a self propelled Terra Gator 1803 twin bin pneumatic spreader (AGCO, Duluth, GA) based on data from soil prescription maps and the position of the machine in the field.

VARIABLE RATE FERTILIZATION OF CITRUS IN FLORIDA: PRINCIPLES AND IMPLEMENTATION. Variable rate granular fertilizer spreaders for citrus use sensors, embedded computers, and GPS technology to continuously monitor trees along the row and can be used to make adjustments to the rate of fertilizer delivered to each tree (Schumann et al., 2006a). Granular fertilizer is accurately placed in independent left and right bands under the trees. The amount of fertilizer is regulated according to a GPS-guided prescription map or by the number of sensors that detect a tree canopy in left- or right-hand rows (Fig. 7). Most importantly, spaces with missing trees are never fertilized, which significantly reduces application of unnecessary nutrients, fertilizer costs per hectare, and groundwater pollution while discouraging weed growth. Tree roots, the primary targets for fertilizer applications, are located about under the tree canopy. Thus, the first assumption of VRF is simply that if a canopy and therefore roots are not present, then fertilizer is not applied. The second assumption of 


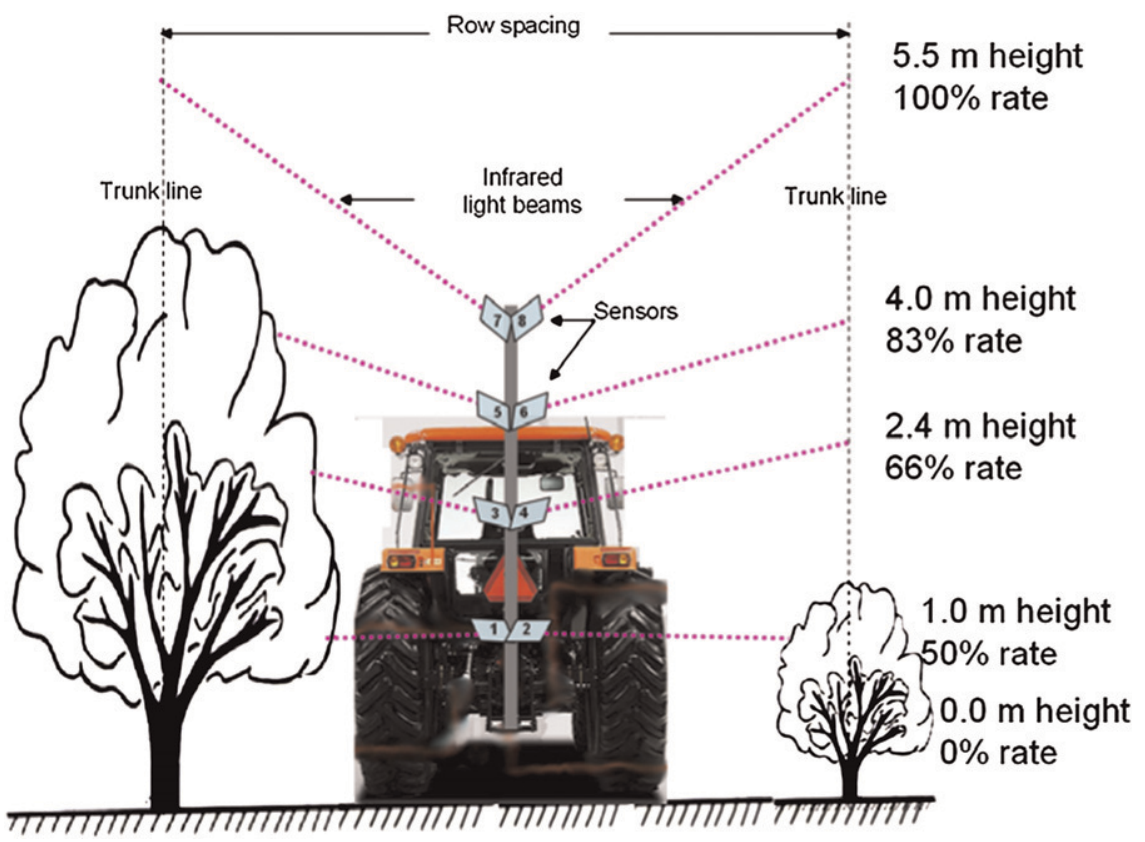

Fig. 7. Schematic diagram of the sensor layout and operation on a variable rate fertilizer (VRF) granular spreader for citrus; $1 \mathrm{~m}=3.2808 \mathrm{ft}$.

VRF is that small immature resets should get less fertilizer than mature trees. Because canopy volume is related to tree height and fruit yield, fertilizer rates can be adjusted based on tree height that is measured "onthe-go" by canopy sensors. Each sensor is responsible for a different range of canopy height, and the cumulative sensor result is used by the variable rate computer controller to adjust the fertilizer rate on each side of the spreader (Fig. 7). Therefore, a fully grown, mature tree will activate all sensors on its side and receive the full fertilizer rate.

VRF in citrus orchards operates on "single tree prescription zones" because each tree in the orchard should be measured and have its own customized fertilizer rate, delivered directly to its root zone. Perfectly uniform orchards with no gaps between canopies will not benefit from VRF. The VRF technology is most effective in orchards with different tree sizes because VRF is designed to exploit that variability. Thus, an orchard containing young trees with non-overlapping canopies, or a mixture of large trees, young trees, and/ or resets will benefit the most from VRF.

"Look ahead" is a type of precompensation implemented in VRF spreaders, which uses the continuous stream of tree size information being collected by canopy sensors. This essential information allows the computer to predict, so that the hydraulic valve and conveyor belt response time, fertilizer particle drop time, and other mechanical delays can effectively be subtracted ahead of the fertilizer placement point. If look ahead is not implemented, the fertilizer placement may be inaccurate due to poor synchronization of rates with trees, especially at varying ground speeds. In citrus studies, look-ahead sensing was able to double the accuracy of a VRF system (Land Manager II; DICKEY-john, Auburn, IL) (Schumann et al., 2006b). Similar variable rate nutrient delivery technology could be used for other horticultural tree crops.

In a recent study, tree canopy sizes ranging from 0 to $240 \mathrm{~m}^{3}$ were measured with an ultrasonic sensor system in a 17-ha 'Valencia' orange (Citrus sinensis) orchard (Q. Zaman, A.W. Schumann, and S. Shibusawa, unpublished). Six $\mathrm{N}$ rates $(0,134$, $168,202,235$, and $269 \mathrm{~kg} \cdot \mathrm{ha}^{-1}$ per year) were applied with a VRF spreader according to a prescription map developed from tree canopy size information. For comparison, half of the orchard received the standard uniform N rate of $269 \mathrm{~kg} \cdot \mathrm{ha}^{-1}$ per year. Soil leachate samples were collected with vacuum lysimeters at 1.5$\mathrm{m}$ soil depth from below the root zones of 36 trees in 18 paired plots. The leachate samples from 10 sampling dates in 2005 were analyzed for nitrate- $\mathrm{N}$ concentration, and leaf samples were analyzed for leaf nutrient concentrations under VRF and uniform fertilization. Trees with excess leaf $\mathrm{N}(>3 \%)$ under uniform fertilization all had smaller canopy volumes (less than $100 \mathrm{~m}^{3}$ ), and constituted $62 \%$ of the orchard. This was evidence of excess fertilization under uniform fertilization management. In contrast, the VRF treatment significantly $(P \leq 0.05)$ decreased nitrate loading from leachates leaving the root zone compared with the uniform treatment. Mean leachate nitrate- $\mathrm{N}$ concentrations for all VRF treatments ranged from 1.5 to 4.5 $\mathrm{mg} \cdot \mathrm{L}^{-1}$ and were below the maximum contaminant level for groundwater of $10 \mathrm{mg} \cdot \mathrm{L}^{-1}$, while those under uniformly fertilized small and large trees were 28.5 and $14.0 \mathrm{mg} \cdot \mathrm{L}^{-1}$, respectively. Most leaf nutrient concentrations were not significantly influenced by the VRF fertilization and were within the recommended optimal ranges. Despite not detrimentally affecting tree nutrition, VRF used $40 \%$ less fertilizer than standard uniform fertilization and therefore also improved orchard profitability.

\section{Focus for future research efforts in precision agriculture}

PA and particularly variable rate technology can maximize nutrient and water uptake efficiency in horticultural crops by keeping water and nutrients in the root zone. Some additional opportunities available for keeping nutrients in the root zone are:

- Improving knowledge of exactly where the crop plants are located. Conventionally planted crop plants cannot be located later with maps and GPS equipment. Initial precise mapping of where seeds are planted solves this problem because then fertilizer spreaders can be guided exactly to the root zones during the growth cycle. Highly accurate realtime kinematic (RTK)-GPS receivers and GPS-guided tractor steering systems can make precision seed mapping possible. Griepentrog et al. (2005) measured the average error between the RTK-GPS seed map and the actual plant map, and found 
it was about 16 to $43 \mathrm{~mm}$, depending on vehicle speed and seed spacing.

- Variable rate irrigation could greatly improve the retention of nutrients in the root zone by customizing the exact soil moisture requirements for different plants in the field. Although technically feasible, this method is currently very expensive to implement.

- Crop canopy quality data from new sensors, in addition to canopy size, would be valuable to distinguish between healthy living and diseased or dead plants. Weak, sick, or dead plants that will not recover should not be fertilized because the nutrients will not be used efficiently in the root zone. Existing canopy sensors tend to measure only size, and can therefore not discriminate between healthy or dead plants.

\section{Literature cited}

Alchanatis, V., Z. Schmilovitch, and M. Meron. 2005. In-field assessment of single leaf nitrogen status by spectral reflectance measurements. Precis. Agr. 6:2539.

Babcock, B.A. and G.R. Pautsch. 1998. Moving from uniform to variable fertilizer rates on Iowa corn: Effects on rates and returns. J. Agr. Resources Econ. 23:385400.

Cambouris, A.N., M.C. Nolin, B.J. Zebarth, and M.R. Laverdiere. 2006. Soil management zones delineated by electrical conductivity to characterize spatial and temporal variations in potato yield and in soil properties. Amer. J. Potato Res. 83:381-395.

Doerge, T. 1999. Defining management zones for precision farming. Crop Insights $8: 1-5$.

Elings, A., P.H.B. de Visser, L.F.M. Marcelis, M. Heinen, H.A.G.M. Boogaard, T.H. Gieling, and B.E. Werner.
2004. Feed-forward control of water and nutrient supply in greenhouse horticulture: Development of a system. Acta Hort. 654:195-202.

Giles, D.K. and D.C. Slaughter. 1997. Precision band spraying with machinevision guidance and adjustable yaw nozzles. Trans. Amer. Soc. Agr. Eng. 40:2936.

Griepentrog, H.W., M. Nørremark, H. Nielsen, and B.S. Blackmore. 2005. Seed mapping of sugar beet. Precis. Agr. 6:157-165.

Jifon, J.L., J.P. Syvertsen, and E.L. Whaley. 2005. Growth environment and leaf anatomy affect nondestructive estimates of leaf chlorophyll and nitrogen in Citrus species. J. Amer. Soc. Hort. Sci. 130:152-158.

Johnson, L.F., D.F. Bosch, D.C. Williams, and B.M. Lobitz. 2001. Remote sensing of vineyard management zones: Implications for wine quality. Appl. Eng. Agr. 17:557560 .

Kim, Y., J.F. Reid, and S. Han. 2002. Evaluation of a real-time $\mathrm{N}$ sensing and fertilizer control. Automation technology for off-road equipment. Amer. Soc. Agr. Eng. Publ. No. 701P0502:102-111.

Ojeda, H., N. Carrillo, L. Deis, B. Tisseyre, M. Heywang, and A. Carbonneau. 2005. Precision viticulture and water status II: Quantitative and qualitative performance of different within-field zones, defined from water potential mapping. XIV Intl. Groupe d'Etude des Systemes de Conduite de la vigne (GESCO) Viticulture Congress. Geisenheim, Germany 2:741-748.

Pelletier, G. and S.K. Upadhyaya. 1999. Development of a tomato load/yield monitor. Comput. Electron. Agr. 23: 103-117.

Pfenning, J., S. Graeff, W. Claupein, and H.P. Liebig. 2007. Use of reflectance measurements to measure $\mathrm{N}$ demand of broccoli plants (Brassica oleraceae var italica). Sixth European Conf. Precision Agr, 657-662.
Radite, P.A.S., M. Umeda, M. Iida, and M. Khilael. 2000. Variable rate fertilizer applicator for paddy field. Amer. Soc. Agr. Eng. Annu. Intl. Mtg., Milwaukee, Paper No. 001156

Schumann, A.W. and Q. Zaman. 2003. Mapping water table depth by electromagnetic induction. Appl. Eng. Agr. 19:675-688.

Schumann, A.W. and Q. Zaman. 2005. Software development for real-time ultrasonic mapping of tree canopy size. Comput. Electron. Agr. 47:25-40.

Schumann, A.W., H.K. Hostler, S.M. Buchanon, and Q. Zaman. 2006a. Relating citrus canopy size and yield to precision fertilization. Proc. Florida State Hort. Soc. 119:148-154.

Schumann, A.W., W.M. Miller, S.A. Cugati, H.K. Hostler, and S.M. Buchanon. 2006b. Optimizing variable rate granular fertilizer spreader performance for single tree prescription zones. Amer. Soc. Agr. Biol. Eng. Annu. Intl. Mtg., Paper No. 061073 .

Sedlak, P., F. Bauer, and A. Neischl. 2001. Control of the quality of operation of industrial fertilizer spreaders in the system of precision farming. Res. Agr. Eng. 47:49-54.

Spaans, E. and L. Quiros. 2003. Precision agriculture to improve management decisions and field research. Proc. 2nd Intl. Wkshp. Mycosphaerella Dis p. 297-302.

Yang, C. 2001. A variable rate applicator for controlling rates of two liquid fertilizers. Appl. Eng. Agr. 17:409-417.

Zaman, Q., A.W. Schumann, and W.M. Miller. 2005. Variable rate nitrogen application in Florida citrus based on ultrasonically sensed tree size. Appl. Eng. Agric. 21:331-335.

Zaman, Q. and A.W. Schumann. 2005. Performance of an ultrasonic tree volume measurement system in commercial citrus groves. Precis. Agr. 6:467-480. 